\title{
6. The broken toy tactic: Clockwork worlds and activist games
}

\author{
Anne-Marie Schleiner
}

\begin{abstract}
The focus of this chapter is on 'activist simulation games,' which are motivated by an activist or political intention on the part of the gamemaker, and which attempt to harness simulation and procedurality in the game to convey the maker's political critique or message to the playing public. Schleiner argues that that the 'toyness' of the world of such games, the miniature abstraction of the model that announces itself as game, not life, contributes to a nullification of the game's critical impact. To break away from this situation, she argues, requires a 'broken toy tactic' of interruption or sabotage that breaks the spell of games' procedural, operational logic.
\end{abstract}

Keywords: Activist games, serious games, procedurality, simulation, toy worlds, no play

Toy trains circle through a 1:25 scale model of traditional Dutch buildings and landmarks in the miniature city of Madurodam. Miniature cargo ships float along canals and toy delivery trucks loop around a peripheral freeway. These vehicle circulations have followed a reliable daily schedule ever since the tourist attraction was constructed in $195^{2}$ as a memorial to George Maduro, a young Jewish member of the Dutch Nazi resistance. On travel blogs, visitors remark on the punctuality of the miniature city's transportation, recalling their childhood fascination with the moving parts of Madurodam's toy vehicles. Despite the vacant artificiality of the setting, the frozen-in-place postures of Madurodam's doll-citizens, and the peculiar conglomeration

Glas, R., S. Lammes, M. de Lange, J. Raessens, and I. de Vries, eds. 2019. The Playful Citizen. Civic Engagement in a Mediatized Culture. Amsterdam: Amsterdam University Press. DOI: $10.5117 / 9789462984523 / \mathrm{CHO} 6$ 
of national landmarks in one Disney-like city, young and old still delight in the liveliness of the toy city. ${ }^{1}$

With similar interlocking, repetitious movements, like the hypnotic circuitous loops of a model train set, miniature computer game worlds draw the player into convincing abstractions of everyday operations. The hum of movement within a computer game, the automated circling of artificially alive 'non-player' characters, the scheduled passages of toy-like trains and vehicles and the movement of the sun and clouds, synchronize with outside-the-game spheres of operations, convincing the player of the parallel efficacy of the clockwork model. Bespelled by these motions, the player believes in the model regardless of whether game characters appear in photorealistic detail or are capable of a convincingly human, artificially intelligent conversation. Moving interlocking parts conform to a functional, rational diagram of a rhythmic clockwork universe where all is running as it should.

Similar to the application of simulation in the field of computer science, all manner of lively processes from the world are modeled into game worlds, from gardening to crowd fluxuations. ${ }^{2}$ For instance, in the classic simulation genre game, designer Will Wright's The Sims (Maxis 2000), the domestic life of a suburban North American family is simulated in a doll-house-like game where vivacious Sims people eat, walk, urinate, socialize, and speak in 'Simlish,' a pseudo-language of emoticons. In this chapter, I will in particular draw on the investigations of Gonzalo Frasca (2001), Ian Bogost (2008), and Chaim Gingold (2003) into simulation and the 'procedural' logic of games, the lively processes and movements that unfold each time a game is played. Much of this theorization comes out of a post-graduate study program directed by Janet Murray, who initially proposed that a computer game is a cultural work produced by a "procedural author" $(1997,153)$.

Although my argument in this chapter will be informed by the substantial inroads that Bogost and others have wrought theorizing the dynamic

1 Last time I visited Madurodam, on a weekday in June of 2011, the aging toy city seemed somewhat forgotten by the Dutch, although it was still attended by busloads of Indian and Chinese tourists.

2 The term 'simulation' also invokes post-modern philosopher Jean Baudrillard's theories of simulation and 'simulacra', especially in reference to Disneyland and suburbia. Yet, Baudrillard's interest in simulation seems primarily bound up with describing the artificiality of a post-modern capitalist condition that has replaced authentic experience, a mourning for a loss of authenticity. Simulation in computer games, on the other hand, like in computer science, takes the artificiality of the model as a given without moral qualms - even as such models attempt to improve their fidelity to real life processes assumed to still be running outside the game. 
procedural rhetoric of games, what has been somewhat overlooked, even by critics of 'procedurality' like Miguel Sicart (2011), is a closer consideration of procedurality itself. In particular, I am interested in the impact of these 'gamic' procedures on political or social critique in what are called 'serious games.' Serious games is a grab-bag appellation for diverse educational, training, and activist games, which I will for this chapter primarily limit to the analysis of 'activist simulation games,' games such as Climate Defense (Auroch Digital 2013) or Sweatshop (Littleloud 2011) with explicit political and/or persuasive ambitions on the part of their concerned citizen makers. A one- or two-person developer is often solely responsible for all aspects of the game-making in these independent small companies, including art direction, design, programming, and playtesting. The maker of an activist simulation game attempts to make use of mimetic algorithms in the game to present a persuasive argument in motion, to launch a social, environmental, or other activist critique, or to open a political question. As more ordinary citizens come of age among the 'ludoliterate' versed in the language and genres of gameplay, relatively easy to produce casual games are becoming an attractive vehicle for political action (Raessens 2010). Still, we are only beginning to forge an understanding of how such games both serve and fail as activist tools, as tactics, among others, available to the concerned citizen. Therefore, my definition in this chapter of an 'activist simulation game' is both: a. motivated by an activist or political intent on the part of the game-maker, and $b$. attempts to harness simulation and procedurality in the game to carry the maker's political critique or message to the playing public. ${ }^{3}$

A definition relying partially on the game-maker's intention does encounter inherent contradictions, as when, for example, games not explicitly intended to be politically persuasive, such as entertaining war games, can easily be read as propaganda. But the desire on the part of the game-maker to use a game as a form of political argumentation with a broader public, both when it succeeds and fails as it is countermanded by aspects of the game, is a primary tension that I will explore in this chapter. Referring to this difficulty in designing serious games Mary Flanagan writes: "These play spaces must retain all the elements that make a game enjoyable while effectively communicating their message" (2009, 249).

3 The activist simulation game contrasts to another common variant of serious games where a 'normal' entertaining game is interspersed with packets of 'serious' or pedagogic information that the player swallows like cans of vegetables in between courses of fun. 
In an activist simulation game, a play move is not only an inconsequential act of fun, but also carries symbolic weight by referencing real issues and world problems, for instance signifying whether a member of a threatened species like the polar bear in Polar Plunder (AIMS Games Center 2013) can find enough food under the ice for her cubs despite Arctic climate change. And yet, in spite of this added worldly weight and consequentiality, it is often difficult to take serious games seriously. Although game-makers set out to shock players with a moving diagram of harmful and tragic operations, players conversely succumb to the enchantment of lively, toy-like, mechanical processes within the miniature, abstracted clockwork game world, no matter how damaging the actual operations in the exterior world, regardless of how many dolphins are killed or how many tracts of rainforest are destroyed. The game asks to be played and mastered, inviting the player to enter into its cause and effect mechanical loops, regardless of the consequences-it is only a game, after all.

The 'toyness' of the world of the game, the miniature abstraction of the model that announces itself as game, not life, contributes to this nullification of the game's critical impact, as I will discuss further on. Moreover, I will argue that the operational movements running inside the game induce a complacency akin to what Martin Heidegger referred to as "everyday sight," a way of "Being-in-the-World" already familiar to us from procedural interactions in the world outside the game $(1927,107)$. In order to better understand the effect of the procedurality of the game on the player, in this chapter I will draw on what may seem an unlikely and acontemporous source from outside the fields of game studies and computer science, where procedurality itself has often been accepted at face value as a positive rhetorical tool within games. ${ }^{4}$ In Being and time, his primary work devoted to forwarding a temporal, embodied phenomenological understanding of human existence, Heidegger theorized a common, everyday mode of being (ontology) and a mental framework that he understood as a submersion within the everyday circulations and procedures of the work-a-day, social world (Ibid., 78). This practical view of the workings of the world is what he refers to alternately as "everyday sight" and "circumspection" (2003, 107). A railway line transports workers from the suburbs to the city; the

4 Heidegger is often considered an apolitical philosopher, or judged for his Nazi era actions as a university administrator in Freiburg, and therefore might seem distant from political critique or philosophy. Even so, his deconstructive philosophical method was highly influential for critical theory in the latter half of the twentieth century, and informed, for instance, the deconstructive methodology of Jaques Derrida. Also, Heidegger's phenomenological framework impacted political philosophers like Hannah Arendt and Georgio Agamben. 


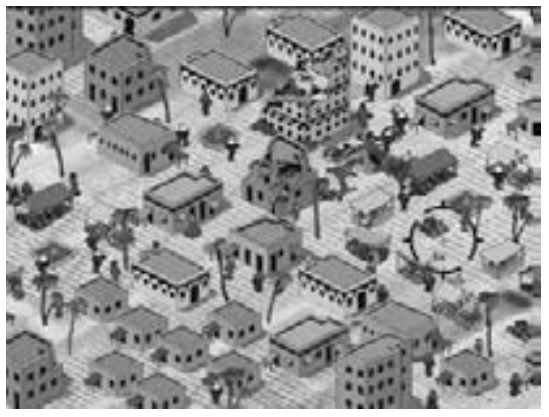

6.1: September 12th - Game screenshot.

suburban train stops to let a passenger off at an inner-city station guarded by a vigilant conductor who steps back and forth on the station platform. Such an interlocking set of functional workings, which we also see running compellingly in the toy city of Madurodam, is supplementary to Heidegger's "Dasein in the They," an immersed everyday orientation within the common world $(1927,167)$. We seldom question or "disclose" our place or the place of others in such work-a-day utilitarian operations, for to do so continuously would impede our ability to plug into the "equipmental workshops" we use to take care of daily business (Ibid., 105).

The dilemma that confronts the activist game-maker is that the very procedural logic of the simulation game that he or she hopes to harness for a provocative critique has a bewitching effect on the player, comparable to Heidegger's state of fascinated absorption in the practical workings of the world $(1927,107)$. Examples of equipment in Being and time, of clocks, hammers, planes, and needles, speak of a more rhythmic, mechanical, Industrial Age, but almost a century later, well into the Information Age, much of our world is still composed of functional, instrumental relations, on and off the screen (Ibid., 99). Circuitous operationality has found yet another abode in the weightless, abstract toy workings of computer games.

And yet there are exceptions to this rule of the genre, ways for concerned citizens to design games that snap the player out of the hypnotic circle of toy operationality, via what I will refer to as the broken toy tactic. A rupture in the game catapults the player outside the comforting and rewarding operational sphere of the clockwork game world and induces him or her to critical reflection, contestation, or action. While analyzing two popular activist games closely, I will argue that the player's shift from fascinated immersion in moving game world operations to a disturbed confrontation with a malfunction of play mirrors Heidegger's anxious illuminations of the operational clockwork loops of the world that might arise when a tool, 
like his oft invoked hammer, is broken or missing $(1927,102)$. A break in the smooth functionality of the game discloses its operational logic in greater "totality" (Ibid., 105). For Heidegger, a "clearing" of everyday sight uncovers the disquieting temporality of "the who's" existence, as well as illuminating his possibilities (Ibid., 167). Yet, in the hands of the concerned citizen game-maker, this unsettling existential pause or stop, this interruption of the game's workings, is also a moment ripe for critical reflection and evaluation that precedes the formation of a political stance and possible action, the intended transformation of 'games for change.'

\section{Overseers of toy world operations}

Let's enter into a closer comparison of toy world operations at work in two widely played pioneering activist simulation games. The player of Uruguayan Gonzalo Frasca's airstrike simulator game, September 12th (Frasca 2003a) assumes a 'god' or 'bird's-eye' position overlooking a Middle Eastern city from above (see Figure 6.1). This is similar to the perspective on Will Wright's classic SimCity (Maxis 1989) where the player as city planner constructs and manages a city from above. In fact, many simulation games, following the genre template set by SimCity and The Sims (Maxis 2000), position the player as a distant overseer of automated, minutely scaled, toy working worlds.

The goal at the outset of September 12th, similar to many commercial war games released after the terrorist attacks in the United States on September 11, 2001, appears to be to eliminate terrorists from the streets of a Middle Eastern city, identifiable by their gray robes and machine guns. But as the game proceeds, the player recognizes that the more frequently he launches missiles on the terrorists in the city, the more neighboring civilians, including women and children, are converted into terrorists. Forging a rational feedback loop between the player's actions and visible outcomes in the game environment, September 12th simulates an escalating cycle of conflict exasperated by the War on Terror. This interactive, escalation between player and game becomes a dynamic, interactive argument for "violence begets violence." Thus, the game procedurally makes a case for peace via the interactive simulation of strife between the terrorists and the player - who is cast in the role of an air force striker.

But here we may be slightly misled in applying Frasca's own belief in the rhetorical efficacy of simulation to the analysis of the game (2003b). The cycle of the escalation of violence largely becomes illuminated in a critical light because the game does not work properly as a game - the only way 
to 'win' the game would be to abstain from playing, from interacting with the game! On the flip side of the 'positive' simulation of a damaging cycle of the escalation of violence, lies a negative argument for non-intervention, for non-engagement, a 'no play imperative' in either war or games. Paradoxically, can the simulation of a harmful process only become visible (disclosed) to the player, and thereby leveraged as critique, if the game is made frustratingly unplayable, in effect rendered a broken toy? Before we continue with this question, let's take a few moments to consider how procedurality and simulation have been understood in game scholarship thus far.

Murray was one of the first to call attention to the procedurality of games and electronic media. According to Murray,

[p]rocedural authorship means writing the rules by which the texts appear as well as writing the texts themselves. It means writing the rules for the interactor's involvement, that is, the conditions under which things will happen in response to the participant's actions. It means establishing the properties of the objects and potential objects in the virtual world and the formulas for how they will relate to one another. $\left(1997,15^{2-153)}\right.$

Bogost refers to the rhetorical impact of such gamic procedural mechanisms on the player as 'procedural rhetoric': "I suggest the name procedural rhetoric for the practices of using processes persuasively, just as verbal rhetoric is the practice of using oratory persuasively and visual rhetoric is the practice of using images persuasively" $(2008,125)$. As a rhetorical form, game procedurality appears to be an important new form of communication available in the public political sphere. Similarly emphasizing the communicative power of gamic procedures, according to Frasca, a game designer or 'Simauthor' (simulation author) communicates via the rules, logical processes, and algorithms in the game that model the trajectory of outside the game workings and outcomes:

Whoever designs a strike simulator that is extremely hard to play is describing his beliefs regarding social mechanics through the game's rules rather than through events. [...] They are not only able to state if social change is possible or not, but they have the chance of expressing how likely they think it may be. (2003b, 228)

Activist game-makers such as Frasca therefore believe it is possible to harness the procedures of the game to mimic the probable outcome of a military assault, and to thereby communicate a particular belief about the workings 
of the world to the player-citizen, a citizen who may have voting rights and live in a nation with influence over the course of the war. Simulation games deliberately encourage the forging of correspondences from inside-the-game actions, procedures running within Johan Huizinga's "magic circle" of play (1950), to external spheres of action, so as to provoke a confusion that Bogost dubs as 'simulation fever': "But for the magic circle to couple with the world, it must not be hermetic; it must have a breach through which the game world and real-world spill over into one another" $(2006,136)$. Therefore, for the purposes of this discussion, what is important from Huizinga's much-cited and challenged magic circle is the relation between procedures running inside the game and those outside the game.

Worldly goings-on, when transposed via simulation to the game sphere or magic circle, become magically enchanting because they are miniature toy-like abstractions. My application of the magic circle to contemporary simulation games is not intended to imply that such digital games are magical, sorcerous rituals, as in Daniel Pargman and Peter Jakobsson's (2008) critique of the contemporary usage of Huizinga's term. The movement of causal loops within the game exerts the more mundane, everyday magic of the toy miniature, what Chaim Gingold (2003) refers to as a "miniature garden," a spatially reduced, abstracted world like a Japanese garden, model train set, or a doll house. Over the course of his Master's thesis, also conducted at Georgia Tech, Gingold expands on the term he encountered in an interview with Shigero Miyamoto, the influential Japanese game designer of Nintendo computer games. Gingold writes:

[A] garden has an inner life of its own; it is a world in flux which grows and changes. A garden's internal behaviors, and how we understand those rules, help us to wrap our heads and hands around the garden. [...] Gardens, like games, are compact, self-sustained worlds we can immerse ourselves in. $(2003,7)$

The reduction in scale and in complexity in a Japanese garden, the scaling down from forest to tree, from lake to pond, serve in a game as a cognitive aid for the player's apprehension of the systematic clockwork world, a miniature sphere of operations.

The simulation game's 'procedural argument' intentionally blurs the line between the miniature game world and the outside world, but there are important differences between the operations running on either side of this fence or ludic border. Although all games have dynamic, timebased procedures, not all of these play moves make much sense outside 
the game-in other words, to state the rather obvious, not all games are simulation games. For example, when a player makes a move in checkers, this does not correlate to a specific action undertaken in the world outside the game. In this way, the falling, colorful squares of Tetris (Pajitnov 1984) are just that, falling colorful squares. These primarily signify play moves. In such abstract games, actions procedurally advance the game forward toward a goal (or multiple goals) triggering wins and losses. By contrast, in the simulation game, actions and processes have a double signification as both gamic procedures and as metaphoric actions.

And yet this added layer of metaphoric significance does not mean that the player will reflect critically on the simulated operation in activist games, as will become apparent in the following example. By way of comparison to September 12th, let's now consider another widely played, free for download, activist simulation game that affords the player an overview of a miniature toy world. Similar to September $12 t h$, Paulo Pedercini's farcical McDonald's Video Game (Molleindustria 2006), simulates a harmful operation, in this case, an environmentally destructive fast food corporate industry. McDonald's Video Game is structured as a managerial simulation game, and although designed and programmed entirely by Pedercini, the prolific creator behind Molleindustria, the game implements a slick graphical user interface button panel (see Figure 6.2) reminiscent of commercially produced The Sims. The McDonald's Video Game player alternates between managing four distinct production cycles: a. overseeing farm production; b. administering a cattle feedlot; c. managing a chain of hamburger-grill workers; and d. negotiating policies and marketing campaigns in 'corporate headquarters.' The challenge of the game is to effectively multitask, manage, and maintain the production routines in all four areas without letting one slip. As the player's skill improves, outcomes of actions in one sphere of operations have ramifications elsewhere in the game. For instance, if not enough cattle are raised, negative consequences arise further up the supply chain, ultimately effecting the McDonald's corporation bottom-line. Although McDonald's Video Game periodically discloses snippets of textual information about fast food industry practices, it is this simulation of lively processes that imparts a convincing overview of interlocking cycles of fast food bio-production, from deforestation to raising enough cattle for meat to fastfood public relations campaigns.

Despite recurrent dips into bankruptcy, McDonald's Video Game operates so well as managerial training software with the management of a miniature, 


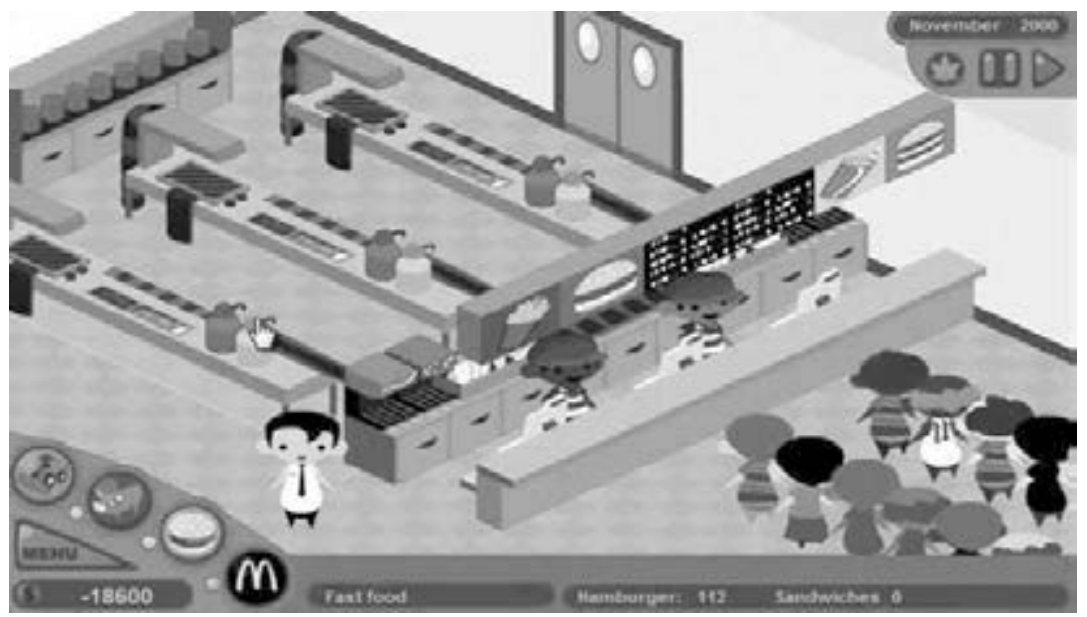

6.2: McDonald's Video Game - Game screenshot.

toy-like, cheerful cow and hamburger world that the ironic subtext of this being an unethical business practice is often missed by players. For instance, when my game design students in Singapore played McDonald's Video Game, they seemed largely unconcerned about the detrimental side effects of this type of production on workers, animals, consumers, or the environment. They were willing to undertake whatever was necessary to keep the game system alive and the McDonald's corporation above the bottom line, even adding diseased cows to the food chain.

\section{The enchanting ordinariness of toy world equipment}

Unlike the vehicles circulating in the toy model city of Madurodam, games like September 12th and McDonald's Video Game require interaction from the player via buttons or a graphical user interface (GUI), conventionally organized into an instrumental dashboard at the edge of the screen. September 12th presents the player with a weapon for targeting and shooting the terrorists; McDonald's Video Game offers the player a colorful toy-like button interface of slaughterhouse machinery to first convert the livestock into hamburgers, and then a different range of equipment for converting hamburgers into dollars. This observation on the equipment of the game interface may seem obvious, but it is this very ordinariness in game interaction that poses another challenge to critical and activist game design because 'equipmental' interactions with game procedures contribute to the player's 
'everyday sight.' In a chapter of Being and time entitled 'The worldhood of the world,' Heidegger describes the equipment required for his everyday operational view of 'Being-in-the-World': "In our dealings we come across equipment for writing, sewing, working, transportation, measurement. [...] A totality of equipment is constituted by various ways of the 'in-order-to,' such as serviceability, conduciveness, usability, manipulability" $(1927,97)$.

When observable in the clockwork toy world, these equipmental operations impart everyday common sense. Referring to the simulation of a natural cycle in a clock, Heidegger writes: "In a clock, account is taken of some definite constellation in the world system" $(2003,72)$, and further on he writes: "When we make use of the clock-equipment, which is proximally and inconspicuously ready-to-hand, the environing Nature is ready-to-hand along with it" (Ibid., 101). In other words, those earthly relations that are simulated or incorporated in the equipment, such as the movement of the sun from day to night being replicated in the clock, are easily 'discovered' and naturalized in the 'clock-equipment'.

Equipment, or the "ready-to-hand" is easy to see, contrasting to Heidegger's "presence-at-hand," the term he uses to refer to the sounds and colors of perceived but not yet differentiated "reality," such as a rumble of noise that upon reaching the ear does not quite resolve into the screech of a passing motorbike $(1927,228)$. Unlike the confusion that an intrusion of "presence-at-hand" reality might occasion, the equipmental operations of the ready-to-hand world are easily apprehended, made sense of, or 'discovered.' The equipment's functionality seems obvious, running smoothly in plain sight, in the common-sense realm of 'the They.' Naturally, the player would want to use the available buttons to operate the farm machinery and produce hamburgers. Thus, simulation games simulate alleged processes from outside the game sphere in plain view, invoking the everyday perspective of how things work, the operations of fast food production, or of an efficient airstrike. If we apply an extended Heideggerian interpretation, 'equipment' refers not only to interface buttons, but also to the larger operations (in his terms 'workshops') that these buttons trigger or manipulate. For instance, September 12th presents the player with a weapon for targeting and shooting the terrorists; while McDonald's Video Game offers the player a colorful toy-like button-interface of slaughterhouse machinery to turn livestock into hamburgers, and then a different range of equipment for turning hamburgers into dollars.

Although ready-to-hand equipment is easily discoverable, it is also hidden, in another sense. The familiarity of everyday sight or circumspection, conceals "the totality" of a clockwork operation, the in-order-to relations that 
it is connected to, including objects and persons at a distance (Heidegger 1927, 105). Immersion in the clockwork world's operations is a state of "concernful" absorption that is to a certain extent blind and alienated, not only to its own existence, but to the larger repercussions of the operation (Ibid., 101). The game's movement compels the player to accept its operations as ordinary, as unquestionable cycles of everyday life, unfolding within plain view or, to be more precise, in relation to simulation genre games, within the elevated plain view of the great overseer of the toy world operations. The challenge that then confronts the concerned citizen game-maker is that no matter what these simulated operations are, as they run with the evocative mimicry within miniature toy worlds, they acquire everyday currency and uncritical acceptance among players via the motion of their interlocking, toy-like workings.

\section{Player vs. game}

But do the toy world's procedures really subsume the player to such an extent? Is the operational functionality of the game truly so bewitching? Furthermore, an allegation could be made that Bogost's rhetorical transmission of procedural game logic from the sender (the game-maker or 'Simauthor') to receiver (the player) is limited by a communications model of sending and receiving. The player in this analysis, even while interacting with the game, becomes a passive recipient of rhetoric in motion. In a similar vein, Sicart critiques the limited role that players are afforded in designer-weighted, instrumental 'proceduralist' game studies, writing that players "are important, but only as activators of the process that sets the meanings contained in the game in motion" (2011). Are game designers, then, the only ones afforded the role of agents of engaged ludic citizenship? In support of player agency, Frasca proposes that players, not only game designers, potentially impact the ultimate rhetorical "outcome" of a game by channeling the course of play into directions unimagined by the game-maker $(2003 \mathrm{~b}, 228)$. Frasca calls upon Brazilian theater director Augusto Boal's "Theater of the Oppressed" as a model for how a game can depart from Aristotlean narrative closure. Frasca writes "one of [Boal's] most popular techniques, re-enacts the same play several times by allowing different audience members to get into the stage and take the protagonist's role," resulting in unforeseen outcomes (Ibid.).

For instance, such player-directed outcomes are evident in the spectacular demise of artificial game life, of entire families and their pets, in a dark genre 
of the Sims known as 'Disaster Sims.' The player's influence on the game's rhetorical outcome in such cases amounts to a breaking of the original game designer's 'script' to breed a suburban American family. With these morbid, broken games, often ending in fire, we return via a different path, following the player's initiative rather than the game-maker's, to derailed and broken game equipment.

On the other hand, when the toy is not broken, when the system is running without interruption, as when the player engages with the productive fast food mechanizations of McDonald's Video Game, the player remains blind to its workings even as she plugs into its persuasive everyday perspective. Losing track of time, the player immerses herself in a sequence of game challenges that, if designed well, alternates rewards (points, bonuses, and additional tools) with escalating peaks of difficulty, oscillating within what psychologist Mihaly Csikszentmihalyi refers to as a pleasurable "flow state" between challenge and skill $(1990,74)$. Thus, the player's fascinated state of absorption during gameplay suggests a loss of agency to the game's mechanics, except for when the player willfully alters the course of the game's 'oppressive script'.

Similarly, again from the realm of phenomenological philosophy, Heidegger's student Hans-Georg Gadamer makes the inverse proposal that the game plays the player rather than the player the game (1975). Gadamer conducted an inquiry into aesthetics and art that brought him to the phenomenology of play. Gadamer's player gives up his will to the game while performing the reflexive moves demanded by a game: "The structure of play absorbs the player into itself, and thus frees him from the burden of taking the initiative, which constitutes the actual strain of existence" (1975, 105). The player merges with the game, entering into an ongoing interactive, reflexive feedback loop: "What happens to us in the experience of art, Gadamer suggests, is very much like what happens to us in play: we lose ourselves" (Weinsheimer 1985, 102). Unless the player is forced to reflect upon correspondences reaching beyond the game, the player's critical and reflective capacity, political or otherwise, is easily bewitched amid the movement of game actions. Reacting with neither doubt, nor, on the contrary, belief, the player flows with the game's operational allegations about how the world works.

Only when the model is broken or interrupted by a renegade player, such as the maker of a Disaster Sim, or a game cheater or breaker, or through some form of sabotage installed by the game-maker, does the toy world's algorithms and workings become visible. Frasca's September 12 th catapults the player outside the cozy assumptions of the clockwork game world and 
the comfortable correlations between rewarding player proficiency with toy weapons and 'how things work.' The brokenness of September 12th manifests in that playing well delivers loss, subverting the expectation of the player to master a rewarding challenge of eliminating terrorists. In McDonald's Video Game, on the other hand, the very operationality of the model of fast food production cycles transmitted to the player overcomes the game's critical impact. Beautiful toys that run too well are always enchanting, no matter how ugly the outcome of their workings. The player is lost in the game.

\section{Broken toys and the no play imperative}

The operational logic of the game takes hold. A player's action inspires a resulting reaction on the part of the game. The game, in turn, compels the player to further reflexive play moves and if the game is designed well, the player loses herself, losing even a sense of the passage of hours and days, within the game, absorbed into the game's workings, immersed in a feedback loop, Gadamer's aesthetic union of player and game. The player performs a role among other processes running within the clockwork world through interaction with the game machine and the management of its simulated processes. Like the imprint of a popular tune that demands to be liked through its repeated exposure to the ears, players unreflectively absorb the logic of military operations, internalize the production cycle of hamburgers, and flow with the hum of tractors. How satisfying when at least the toy world is operating as it should.

In the rational, operational spheres of games, as in the instrumental spheres of life, one's everyday perspective turns away from suffering and the consequences of damaging human operations. Most feel powerless to disengage from, halt, or redirect harmful goings-on that are naturalized. Players flee their own mortality to the artificial circulations of ageless clockwork, toy worlds. In this sense, Madurodam's endless ship and train circulations are a soothing and forgetful memorial to the untimely demise of young George Maduro.

A tactical recipe for the activist simulation game consists then of two steps, first a positive, then a negative; first to constructively program a simulation of a harmful operation from the world into the game, followed up by either a game-maker, or player instigated interruption, or sabotage that breaks the spell of the game's movement and procedurality, thereby illuminating its operationality in a critical light. Absorption in 
the everyday world of 'equipmental' dealings and transactions are broken at this rift of 'in-order-to' relations among entities, things, and persons. Induced to a discomforting re-evaluation and analysis of the games' operational logic, the player performs a critical diagnosis of the wrongness or rightness of the broken play equipment. After being subjected to the broken toy tactic, a worldly operation's common sense, the everyday claim on existence comes into dispute, becoming a matter of critical concern for the citizen-player.

What is paradoxical with the broken toy tactic is that the game and activist critique remain in the last instance incompatible - only by interrupting or ejecting the player from the game, the no play imperative, is a critique illuminated and a political questioning made possible. Moreover, the intended effect of such games is not just a break in the game, but also the possibility of putting a stop to the destructive worldly procedure that is being simulated. The no play imperative extends beyond the game to the refusal to be a 'player' in the harmful processes of the world, a refusal to play at war, a refusal to play at the exploitation of the environment in the production and consumption of fast food. Thus, the most earnest mixture of politics and games seems to be delivered in games that do not believe in playing per se, but in the impossibility of separating the world and game, of separating procedurality in one realm or the other on either side of the ludic border. The activist game attempts to catapult the player from absorption in the clockwork toy world, to a realm of politics that he or she is otherwise quite busy avoiding.

\section{Acknowledgments}

This chapter is a rewritten version of the chapter 'Clockwork worlds: Activist games, harrowing missions, and broken toys' from A. M. Schleiner. 2012. Ludic mutation: The player's power to change the game. $\mathrm{PhD}$ thesis University of Amsterdam. See also Schleiner (2017).

\section{References}

AIMS Games Center at Miami University. 2013. Polar Plunder. [Android]. Miami, FL: Miami University. Game.

Auroch Digital. 2013. Climate Defense. [Android]. Bristol: Auroch Digital. Game. 
Bogost, I. 2006. Unit operations: An approach to videogame criticism. Cambridge, MA: The MIT Press.

- 2008. The rhetoric of video games. In The ecology of games: Connecting youth, games, and learning, ed. K. Salen, 117-140. Cambridge, MA: The MIT Press.

Csikszentmihalyi, M. 1990. Flow: The psychology of optimal experience. New York: Harper \& Row.

Flanagan, M. 2009. Critical play: Radical game design. Cambridge, MA: The MIT Press.

Frasca, G. 2001. Videogames of the oppressed. MA thesis: Georgia Tech University. http://www.ludology.org/articles/thesis.

-. 2003a. September $12^{\text {th }}$. [browser]. Newsgaming. Game.

- 2003 b. Simulation versus narrative. Introduction to ludology. In The video game theory reader, eds. M. Wolf and B. Perron, 221-236. New York: Routledge.

Gadamer, H. G. 1975. Truth and method. London: Sheed and Ward Ltd.

Gingold, C. 2003. Miniature gardens and magic crayons. MA thesis: Georgia Tech University. http://slackworks.com/ cog/writing/thesis/aesthetics. php\#2.1.

Heidegger, M. 1927/1962. Being and time. New York: Harper \& Row.

- 2003. Political and philosophical writings, ed. M. Stassen. New York: Continuum International Publishing Group.

Huizinga, J. 1950. Homo ludens: A study of the play-element in culture. Boston, MA: Beacon Press.

Littleloud. 2011. Sweatshop. [browser]. Brighton: Littleloud. Game.

Maxis. 1989. SimCity. [multiplatform]. Maxis/Brøderbund/Infogrames. Game. - 2000. The Sims. [multiplatform]. Electronic Arts. Game.

Molleindustria. 2006. McDonald's Video Game. [browser]. Molleindustria. Game.

Murray, J. 1997. Hamlet on the holodeck: The future of narrative in cyberspace. New York: The Free Press.

Pajitnov, A. 1984. Tetris. [multiplatform]. Game.

Pargman, D., and P. Jakobsson. 2008. Do you believe in magic? Computer games in everyday life. European Journal of Cultural Studies 11 (2):225-244.

Raessens, J. 2010. Homo ludens 2.o: The ludic turn in media theory, inaugural address. Faculty of Humanities, Utrecht University, the Netherlands.

Schleiner, A. 2012. Ludic mutation: The player's power to change the game. PhD thesis University of Amsterdam.

- 2017. The player's power to change the game: Ludic mutation. Amsterdam: Amsterdam University Press. 
Sicart, M. 2011. Against procedurality. Game Studies 11 (3). http://gamestudies. org/1103/articles/sicart_ap.

Weinsheimer, Joel C. 1985. Gadamer's hermeneutics: A reading of truth and method. New Haven, CT: Yale University Press.

\section{About the author}

Anne-Marie Schleiner is engaged in gaming and media culture in a variety of roles as a critic, curator, activist, artist, and designer. She has participated in art residencies and given workshops in Germany, Belgium, Spain, and Mexico. She has exhibited in international galleries, museums, and festivals. Documentation of her performative culture work is available in the Video Data Bank. She holds a doctorate in Cultural Analysis from the University of Amsterdam, and her book The player's power to change the game (Amsterdam University Press 2017) explores media art, activism, and game rhetoric. She has taught game design and digital art at universities in the United States, Mexico, and Singapore, and is a Lecturer in Design at the University of California, Davis. 